\title{
PRESENTACIÓN
}

\section{OTRA VEZ EL PUEBLO}

A cincuenta años del triunfo de Salvador Allende en las urnas, revisitar ese tiempo de utopías, compromisos colectivos, de épicas, éticas y estéticas construidas en plural no resulta solo un ejercicio de memoria, sino una demanda necesaria de reflexión política a la luz de un presente que en Chile parecía congelado, pero que luego del estallido social del 18 de octubre de 2019 hizo saltar todos los relatos con que las élites, de manera transversal, desde la derecha a la izquierda concertacionista; desde el empresariado hasta la tecnocracia de centro izquierda, habían construido para este "jaguar" de América Latina, para el "campeón del barrio" en materia de estabilidad económica y social. Un campeón que ocultaba las escandalosas cifras negras en niveles de exclusión social, concentración de la riqueza e inequidad.

Porque al igual que en 1970, cuando miles de hombres, mujeres y niños se volcaron a las calles para celebrar el triunfo electoral del primer presidente socialista elegido democráticamente, y las calles de Chile se repletaron de pueblo celebrando el triunfo y apostando a un futuro con derechos sociales que históricamente se les habían negado, medio siglo más tarde los hijos y nietos de ese mismo pueblo que celebró el 4 de septiembre de 1970 irrumpen en el Chile neoliberal para cambiar la Constitución de Pinochet y redefinir los términos de un pacto social que ahora realmente los incluya.

Sin duda, hay una simetría entre el Chile del triunfo de Allende y el que emerge hoy, luego del estallido y del plebiscito del 25 de octubre último, en el que votaron más de siete millones y medio de personas, donde más del 78 por ciento decidió no solo sobre la urgencia de un cambio constitucional, sino también sobre el modelo económico, aunque la élite, arrinconada en el 21 por ciento que rechazó ese cambio constitucional, insista en no escuchar las demandas de salud, educación y pensiones dignas, entre otras que incluyen a los pueblos originarios y a un Estado que pueda garantizar dichos derechos.

Una simetría dada por la irrupción del pueblo como actor fundamental de la gesta de 1970, y del 18 y 25 de octubre recientes, pese a que, en el Chile actual, a diferencia de 1970, con partidos políticos y movimientos legitimados, los partidos de las izquierdas y del progresismo están en crisis de proyectos y de credibilidad, y, además, muy lejos de representar las demandas de los amplios sectores de la sociedad chilena. 
En las páginas siguientes están los contextos y análisis de los distintos sectores sociales que hicieron posible y luego protagonizaron la épica de los mil días de gobierno popular. Es un relato coral de un tiempo de pasiones y de esperanzas, de trabajo incesante, de debates ásperos entre las distintas visiones de las izquierdas a la sombra de los modelos que proyectaban el bloque de la ex Unión Soviética y la revolución cubana con Fidel y el Che. Entre medio, Salvador Allende y su "revolución con empanadas y vino tinto", una revolución democrática que abrió las conciencias y las compuertas participativas de ese pueblo que, sin necesidad de que lo empujaran, se organizó en las JAP y los CUP, en los cordones industriales, en las organizaciones de campesinos y pobladores, creando un poder popular que, más allá de las consignas y de los estereotipos, reflejó a un pueblo con sentido de clase, organizado, reflexivo, a veces crítico con el proceso del "compañero presidente", pero capaz de dar la vida por defender esos mil días de dignidad.

Se trata de un proceso que redefinió los contornos de nuestro país y, por tanto, de nuestra Universidad. De ahí la relevancia de este número de Revista Anales de la Universidad de Chile que reflexiona desde el presente sobre este medio siglo, que coincide con nuevas revoluciones y nuevos sueños de futuro.

En este número nos complace contar con las propuestas elaboradas por Peter Winn, María Angélica Illanes, Joaquín Fermandois, Luis Thielemann, Jorge Montealegre, Azun Candina, Miguel Lawner, Nelly Richard, Fernando Pairican, Gustavo González, Antoine Faure, Ernesto Águila, Fanny Pollarolo y Carlos Ruiz Encina. A estos artículos desarrollados por relevantes voces y protagonistas del triunfo de la Unidad Popular sumamos, en esta oportunidad, la transcripción de tres mesas de conversación que la Vicerrectoría de Extensión y Comunicaciones de la Universidad de Chile organizó en septiembre de 2020, a modo de conmemoración de los cincuenta años del triunfo del gobierno popular.

"Los sueños y conflictos del Chile de la Unidad Popular" convocó a Jorge Arrate, María Isabel Matamala, Verónica Valdivia y Peter Winn; “¿Qué significó el triunfo de Allende para el mundo? Miradas desde la cultura” reunió a Carmen Castillo, Costa-Gavras, Miguel Littín y al rector Ennio Vivaldi; y "A cincuenta años del triunfo de Allende, ¿cuál es el legado para el Chile actual?” sentó a la misma mesa a Carlos Ruiz Encina, Camila Vallejo, Clarisa Hardy y Rodrigo Mundaca. Se trata de conversaciones que tuvieron resonancia al momento de su transmisión y que, con el paso de los meses, aparecen como más urgentes y necesarias para revisar este proceso fundamental.

Asimismo, incluimos tres entrevistas que dan vida, actualidad y movimiento al proceso. Dos de ellas realizadas por los editores de Revista Anales, Francisco Figueroa y Jennifer Abate, quienes sostuvieron una conversación reflexiva y contingente con la diputada Maya Fernández y el alcalde Daniel Jadue, respectivamente, y una tercera 
conducida por la coordinadora ejecutiva de la Cátedra de Derechos Humanos de la Vicerrectoría de Extensión y Comunicaciones, Karen Cea, quien indagó en los recuerdos de Mireya del Río.

El ya tradicional dossier histórico, a cargo de la directora del Archivo Central Andrés Bello, Alejandra Araya, y su equipo, complementa los textos de este número a partir de documentos con foco en los escasos testimonios documentales que los mil días de Salvador Allende dejaron en la Universidad de Chile. "Durante la elaboración de este dossier hemos podido vislumbrar la ausencia de fotografías de la época, de libros impresos y otros tipos documentales que fueron censurados y eliminados", lamenta la profesora Araya.

Cierra esta edición un dossier gráfico que nos ayuda a repensar el periodo de la Unidad Popular como uno de actividad, movimiento, sinergias y esperanzas, que en este caso se materializan en fotografías, afiches y gráficas. Porque todo es, sin duda, un ejercicio no solo de memorias, sino de historias vitales que movieron el mundo.

Faride Zerán Chelech

Vicerrectora de Extensión y Comunicaciones Directora de la Revista Anales de la Universidad de Chile 